\title{
Effect of NIO dopant on structural, optical and electrical properties of CDO thin film by PLD
}

\author{
*Suaad khafory, +Kadhim A. Aadim, *Ghasaq Ali \\ *Collage of Science for women, University of Baghdad, Baghdad-Iraq \\ + collage of Science, University of Baghdad, Baghdad-Iraq.
}

\begin{abstract}
Nickel oxide doped CDO thin films have been deposited at room temperature and in $723 \mathrm{~K}$ with different concentrations of NIO of $x=(0.01,0.03$ and 0.05)Wt\% onto glass substrates by using pulsed laser deposition technique $\mathrm{Nd}-Y A G$ laser with $\lambda=1064 \mathrm{~nm}$, energy $=500 \mathrm{~mJ}$ and number of shots $=500$. the X-ray diffraction (XRD) results reveals that the characteriste deposited(CDO)(NIO) thin films polycrystalline was cubic structure and many peaks (111), (200), and (220)The results it was calculated show that the UV emission is at a constant peak position in the spectra.
\end{abstract}

Keywords: (CDO)1-x(NIO)x Thin Film; structural properties; pulse laser deposition technique; optical properties and electrical properties.

\section{Introduction}

Cadmium oxide is as a compound semiconductor including cadmium and oxygen(1), $\mathrm{CdO}$ is generally used extensively as TCOs with different physical applications (2), especially in the production of optelectronic devices such as in n-type layer of thin films used for solar cell as well as with a result of its high transparency in the visible region of the solar spectrum $(3,4)$, the main properties of $\mathrm{CdO}$ summarized have a solid brown color and exhibit certain intrinsic feature such as high melting point $\quad\left(1500 \mathrm{C}^{\circ}\right)$, high density $(8150 \mathrm{~kg} / \mathrm{m} 3)$, and molecular weight $(128.4 \mathrm{gm} / \mathrm{mol})$, it is also characterized with cubic crystal structure $\{\mathrm{NaCl}$ (fcc) type; lattice constant $\mathrm{a}=0.4695 \mathrm{~nm}\}$.

$\mathrm{CdO}$ has a high electrical conductivity (low, resistivity), which doing an effect of moderate electron mobility and higher carrier concentration arising from native defects of oxygen anionic vacancies and cadmium interstitials(5), in addition $\mathrm{CdO}$ includes an intermediate direct band gap ranging from $2.26 \mathrm{eV}$ to $2.45 \mathrm{eV}$ as thin films, and $2.5 \mathrm{eV}$ as bulk(6), $\mathrm{CdO}$ can be got by heated cadmium directly in air to high temperature of 900 $\mathrm{C}^{\mathrm{o}}$.

Nickel oxide is the chemical compound with the formula NiO. It is notable as being the only well characterized oxide of nickel. The mineralogical form of $\mathrm{NiO}$, bunsenite, is very rare. $\mathrm{NiO}$ can be prepared by multiple methods(7). Upon heating above $450 \mathrm{oC}$, nickel powder reacts with oxygen to give NiO. In some commercial processes, green nickel oxide is made by heating a mixture of nickel powder and water at $1000 \mathrm{oC}$, the rate for this reaction can be increased by the addition of $\mathrm{NiO}(8)$. The simplest and most successful method of preparation is through pyrolysis of a nickel (II) compounds such as the hydroxide, nitrate, and carbonate, which yield a light green powder $(9,10)$.
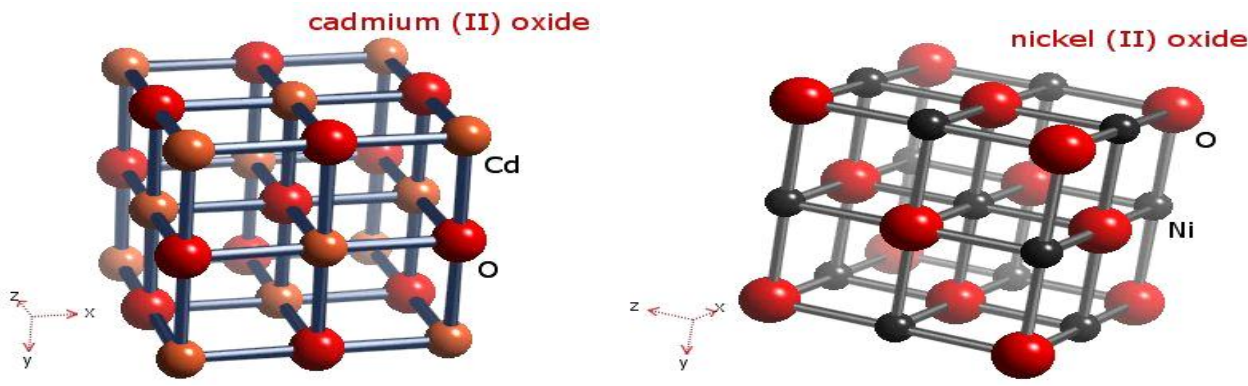

\subsection{Experimental Details}

Cadmium oxide was a purity of $99.99 \%(11,12)$, and Nickel oxide with purity of $99.99 \%(13,14)$, were mixed together at different concentration of $\mathrm{x}=(0.01,0.03,0.05) \mathrm{Wt} \%$ using rotary pump agate pump for 1 hour then the mixture was pressed into pellets of $(2.5 \mathrm{~cm})$ in diameter and $(0.2 \mathrm{~cm})$ thick, using hydraulic manually type (SPECAC), under pressure of 6.5 tonsThe $\mathrm{CdO}: \mathrm{NiO}$ films were deposited on glass slides substrates of $(10 \times 10 \mathrm{~mm})$. The substrate were cleaned with dilated water using ultrasonic bath for 15 minute in order to deposit the films at room temperature. PLD technique was used to deposit the films under vacuum of 
( $8 \times 10-2$ mbar) using Nd:YAG laser with $(\lambda=1064 \mathrm{~nm})$ SHG Q-switching laser beam at $500 \mathrm{~mJ}$, repetition frequency $(6 \mathrm{~Hz})$ for 500 laser pulse is incident on the target surface making with an angle of $45^{\circ}$. The distance between the target and the Nd:YAG laser was set to $(10 \mathrm{~cm})$, and between the target and the substrate was $(2.5$ $\mathrm{cm})$.

\section{1- X-ray Characterization}

\section{Results and Discussion}

The X-ray diffraction (XRD) patetern of the undoped and $\mathrm{CdO}$ doped $\mathrm{NiO}$ thin film deposited on glass substrate is illustrated in Figure 3; the figur reveals a polycrystalline cubic structure of the film. In this diffraction pattern, the peaks at $2 \theta$ correspond to diffraction from (111) and (200) and (220) planes of the CdO cubic phase, respectively.

It is apparent from this figure that all films are preferentially orientated along (111) crystallographic directions and the preferential orientation peak for $\mathrm{CdO}$ doped film became sharper and more intense. This may be attributed to the crystallinity of the $\mathrm{CdO}$ film being improved with $\mathrm{NiO}$ doping.

\begin{tabular}{|l|l|l|l|l|l|l|l|l|}
\hline NiO\% & $2 \theta$ (Deg.) & FWHM (Deg.) & Intensity (a. u.) & $\mathrm{d}_{\text {hkl }}$ Exp. $(\AA)$ & G.S $(\mathrm{nm})$ & $\mathrm{d}_{\text {hkl }}$ Std. $(\AA)$ & hkl & Phase \\
\hline pure & 32.9374 & 0.2969 & 373 & 2.7172 & 27.9 & 2.7110 & $(111)$ & $\mathrm{CdO}$ \\
\hline & 38.2821 & 0.3013 & 346 & 2.3492 & 27.9 & 2.3478 & $(200)$ & $\mathrm{CdO}$ \\
\hline & 55.2068 & 0.2900 & 128 & 1.6625 & 30.9 & 1.6601 & $(220)$ & $\mathrm{CdO}$ \\
\hline 1 & 33.0258 & 0.3200 & 459 & 2.7101 & 25.9 & 2.7110 & $(111)$ & $\mathrm{CdO}$ \\
\hline & 38.1887 & 0.4446 & 432 & 2.3548 & 18.9 & 2.3478 & $(200)$ & $\mathrm{CdO}$ \\
\hline & 43.4100 & 0.3450 & 14 & 2.0829 & 24.8 & 2.0842 & $(200)$ & $\mathrm{NiO}$ \\
\hline & 55.2525 & 0.3067 & 127 & 1.6612 & 29.2 & 1.6601 & $(220)$ & $\mathrm{CdO}$ \\
\hline 3 & 33.0455 & 0.3450 & 299 & 2.7085 & 24.0 & 2.7110 & $(111)$ & $\mathrm{CdO}$ \\
\hline & 38.2053 & 0.4097 & 390 & 2.3538 & 20.5 & 2.3478 & $(200)$ & $\mathrm{CdO}$ \\
\hline & 43.4100 & 0.4530 & 28 & 2.0829 & 18.9 & 2.0842 & $(200)$ & $\mathrm{NiO}$ \\
\hline & 55.3380 & 0.3410 & 90 & 1.6588 & 26.3 & 1.6601 & $(220)$ & $\mathrm{CdO}$ \\
\hline 5 & 32.9262 & 0.5467 & 246 & 2.7181 & 15.2 & 2.7110 & $(111)$ & $\mathrm{CdO}$ \\
\hline & 38.0030 & 0.8297 & 50 & 2.3658 & 10.1 & 2.3478 & $(200)$ & $\mathrm{CdO}$ \\
\hline & 43.2100 & 0.4623 & 30 & 2.0920 & 18.5 & 2.0842 & $(200)$ & $\mathrm{NiO}$ \\
\hline & 55.2443 & 0.4099 & 60 & 1.6614 & 21.9 & 1.6601 & $(220)$ & $\mathrm{CdO}$ \\
\hline
\end{tabular}

Fig1: XRD for $\mathrm{CdO}$ pure and $\mathrm{CdO}: \mathrm{NiO}$ with different concentration at R.T.

\section{2- Atomic force microscopy:}

AFM scans of the surface were carried out to study the change in the surface morphology of the films. AFM images of pure and $\mathrm{CdO}$ doped $\mathrm{NiO}$ films are shown in Fig2. The NiO doped films show smooth surface compared to the cadmium oxide films. The roughness of the films was calculated by the Nanoscope IIIa. The 2.5_m $\times 2.5$ mimages are utilized for measuring the surface roughness of the films. The roughness of the pure $\mathrm{CdO}$ film is measured to be $10.21 \mathrm{~nm}$. Further, the roughness of the samples decreases with increase in doping concentration. The roughness of 1,3 , and $5 \mathrm{wt} . \% \mathrm{CdO}$ doped $\mathrm{NiO}$ measured is $14.35 \mathrm{~nm}, 25.1 \mathrm{~nm}$ and $18.5 \mathrm{~nm}$ respectively.

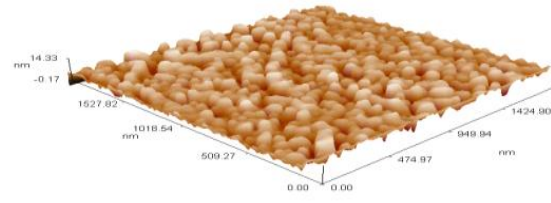

Pure (CDO)

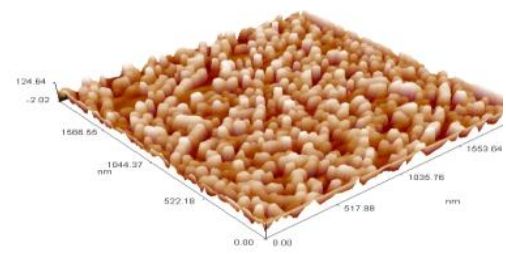

CdO:0.03NiO

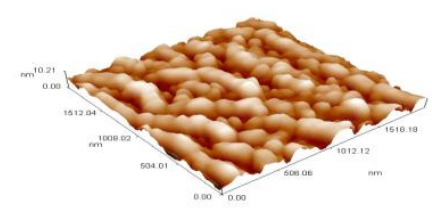

CdO:0.01NiO

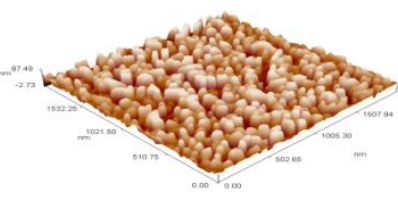

CdO:0.05NiO

Fig2: atomic force microscopy for Cdo pure and for $\mathrm{CdO}: \mathrm{NiO}$ at $\mathrm{R}$.T with different concentration. 


\section{3- Optical properties:}

The absorption spectrum of the $\mathrm{CdO}$ and $\mathrm{NiO}$ doped $\mathrm{CdO}$ thin films deposited on glass substrates is shown in Figur3 below. The Figure shows low absorption coefficient in the UV region, whereas it is transparent in the visible region for $\mathrm{CdO}$ film, and it is decreasing and shifted toward the visible region for $\mathrm{CdO}$ doped $\mathrm{NiO}$ film.

Figure shows the optical transmittance spectra with wavelength from $400 \mathrm{~nm}$ to $1100 \mathrm{~nm}$ of the $\mathrm{CdO}$ doped $\mathrm{NiO}$ thin films. It is observed from this figure that the films show high transmission in the visible region and low transmission in the UV region. The optical transmittance increases for $\mathrm{CdO}$ doped $\mathrm{NiO}$ film.

Assuming direct transition, the dependance of ( $\alpha \mathrm{h} v) 2$ on the photon energy hv is plotted following Tauce relation and the graph is illustrated in Figure .

The extrapolation of the linear part of the above plot to $(\alpha \mathrm{h} v) 2=0$ gives the energy gap values of the $\mathrm{CdO}$ and $\mathrm{NiO}$ doped films, which were found to be about 2.16 and $2.26 \mathrm{eV}$ respectively. It can be noticed from this figure that the value of energy gap is increasing for $\mathrm{CdO}$ doped $\mathrm{NiO}$ film. These values are in a good agreement with the values presented by other workers.

Fig3: Absorption spectra of $\mathrm{CdO}$ doped $\mathrm{NiO}$ at room temperature

Fig4: Transmission spectra of $\mathrm{CdO}$ doped $\mathrm{NiO}$ at room temperature

Fig5: The energy gap of $\mathrm{CdO}: \mathrm{NiO}$ at room temperature.

\section{4- Electrical properties:}

The Hall measurements show that the $\mathrm{CdO}: \mathrm{NiO}$ films deposited on glass substrate are n-type semiconductor, The observed characteristics were supported from the measurement of resistivity, mobility and Hall coefficient as illustrated in table.

The result shows that the mobility and conductivity increase when Cdo doped $\mathrm{NiO}$, where the resistivity decreases.

The type of charge carrier concentration $(\mathrm{nH})$ and Hall mobility $(\mu \mathrm{H})$, have been estimated from Hall measurements. Table below illustrates the main parameters estimated from Hall Effect measurements for $(\mathrm{CdO}) 1-\mathrm{x}(\mathrm{NiO}) \mathrm{x}$ films with different concentration of $\mathrm{NiO}$ at room temperature respectively. It is clear from this table that the all samples have a negative Hall coefficient (n-type), i.e. Hall voltage decreases with increasing of the current. Figure show carriers concentration $(\mathrm{nH})$ and Hall mobility $(\mu \mathrm{H})$ as a function of concentration. It is clear that the carrier concentration $\mathrm{nH}$ increases while the Hall mobility $\mu \mathrm{H}$ increases with the increasing of $\mathrm{NiO}$ content. Increases the density of charge carriers is essentially because of the lowering the potential barrier. While the increasing of mobility is come from the inverse relation between $\mu \mathrm{H}$ and $\mathrm{nH}$.

\begin{tabular}{|c|c|c|c|c|c|}
\hline Material & $\begin{array}{c}\mathbf{R} \boldsymbol{H} \\
\left(\mathrm{cm}^{3 / C}\right)\end{array}$ & $\begin{array}{c}\square \\
(\square . \mathbf{c m})^{\mathbf{1}}\end{array}$ & type & $\begin{array}{c}\square_{\mathbf{H}} \\
\left(\mathrm{cm}^{2} / \mathrm{V} . \mathbf{s}\right)\end{array}$ & $\begin{array}{c}\mathrm{N}_{\mathrm{H}} \\
\left(\mathrm{cm}^{-3}\right)\end{array}$ \\
\hline CdO pure & 10.18E-02 & $2.54 \mathrm{E}+02$ & $\mathbf{N}$ & 25.9 & $6.19 * 10^{19}$ \\
\hline NiO pure & $1.56 \mathrm{E}+05$ & 4.17E-06 & $\mathbf{P}$ & 65.057 & $1.2 * 10^{12}$ \\
\hline CdO :1\% NiO at R.T & 6.12E-05 & $1.98 E+03$ & $\mathbf{N}$ & $1.2 * 10^{-1}$ & $1.02 * 10^{23}$ \\
\hline $\mathrm{CdO}: 3 \% \mathrm{NiO}$ at R.T & $7.50 \mathrm{E}-06$ & $3.26 E+03$ & $\mathbf{N}$ & $1.5 * 10^{-2}$ & $3.3 * 10^{23}$ \\
\hline $\mathrm{CdO}: 5 \% \mathrm{NiO}$ at R.T & 4.42E-05 & $4.14 E+02$ & $\mathbf{N}$ & $1.8 * 10^{-2}$ & $1.3 * 10^{23}$ \\
\hline
\end{tabular}

Fig6: Carrier concentration $(\mathrm{nH})$ as a function of $\mathrm{NiO}$ content at room temperature for $(\mathrm{CdO}) 1-\mathrm{x}(\mathrm{NiO}) \mathrm{x}$ films.

Fig7: Hall mobility $(\mu \mathrm{H})$ as a function of $\mathrm{NiO}$ content at room temperature for $(\mathrm{CdO}) 1-\mathrm{x}(\mathrm{NiO}) \mathrm{x}$ films 


\section{5-DC Conductivity}

Figures below shows the variation of lnod.c versus $1000 / \mathrm{T}$ for $(\mathrm{CdO}) 1-\mathrm{x}(\mathrm{NiO}) \mathrm{x}$ film deposited by pluses laser on glass substrates with different concentration of $\mathrm{NiO} x=(0.01,0.03,0.05) \mathrm{Wt}$. \% at room temperature, with average thickness of $(500) \mathrm{nm}$. From this figure, it is found that there are two stages of d.c conductivity mechanism throughout the temperatures range (283-363K).

Fig8: The relation between $\operatorname{Ln}(\sigma)$ versus reciprocal of temperature $(1000 / \mathrm{T})(\mathrm{CdO}) 1-\mathrm{x}(\mathrm{NiO}) \mathrm{x}$ films with different concentration of $\mathrm{NiO}$ at $\mathrm{RT}$.

\begin{tabular}{|c|c|c|c|c|}
\hline concentration & $\mathrm{E}_{\mathrm{a} 1}(\mathrm{eV})$ & Range $(\mathrm{K})$ & $\sigma_{\mathrm{RT}}\left(\Omega^{-1} \cdot \mathrm{cm}^{-1}\right)$ & $\rho(\Omega . \mathrm{cm})$ \\
\hline pure & 0.045 & $283-363$ & $7.60 \mathrm{E}-02$ & $1.32 \mathrm{E}+01$ \\
\hline 0.01 & 0.036 & $283-363$ & $1.73 \mathrm{E}-03$ & $5.78 \mathrm{E}+02$ \\
\hline 0.03 & 0.033 & $283-363$ & $8.05 \mathrm{E}-05$ & $1.24 \mathrm{E}+04$ \\
\hline 0.05 & 0.011 & $283-363$ & $5.44 \mathrm{E}-05$ & $1.84 \mathrm{E}+04$ \\
\hline
\end{tabular}

The values of the Ea1 at R.T

\section{Conclusion}

CDO doped NIO thin films were successfully deposited on glass substrates using pulsed laser deposition techniqe. The films at R.T exhibited structure of CdO. From the optical transmittance it was revealed that the transparency and band gap increase with doping concentration. In electrical properties we note that decrease of electrical conductivity cause decrease of resistivity in this film at R.T.

\section{Reference}

[1]. Tribble, "electrical engineering materials and device applications" university of Lowa, 2002

[2]. W. Robert, M. Peter and T.Murray, "thin film technology" Litton Educational publishing, Int. New York, 1968.

[3]. K.D.Leaver and B.N Chapman "Thin Films "Wykeham publications (London ) Ltd .(1971)

[4]. T. J. Couttsand D. L. Yong and X. Li, "characterization of Transparent oxides" 1990.

[5]. D. R. Kammler, D. D. Edward, B. G. Ingram, T. o. Mason,"novel compound and solid solution transparent conducting oxides for photovoltaic", journal Electrochemical society processing, 99, pp. 68, 2000.

[6]. Greenwood, Norman N, Earnshaw, Alan, "Chemistry of the Elements", Oxford, Pergamon Press, (1984).

[7]. Pradniak, Pradyot, Publications, "Handbook of Inorganic Chemicals",(2002).

[8]. K. Lascelles, L. G. Morgan, D. Nicholls, D. Beyersmann, "Nickel Compounds", in Ullmann's Encyclopedia of Industrial Chemistry Wiley-VCH, Weinheim, (2005).

[9]. E. Fujii, A. Tomozawa, H. Torii, R. Takayama," Preferred Orientation of NiO Films Prepared by Plasma-Enhanced Metalorganic Chemical Vapor Deposition", Jpn. J. Appl. Phys. vol.35, pp. 328-330, (1996).

[10]. B. Sasi and K. G. Gopalchandran, "Nanostructured Mesoporous Nickel Oxide Thin Films", Nanotechnology, vol. 18, pp.115613115617, (2007).

[11]. M. ortega, G. santana, and A. Morales- Acevedo, "optoelectronic properties of cdo/si photo detectors," solid. State. Electron , vol.44,no.10,pp.1765-1769,2000

[12]. G. singh, I.P.S. kapoor, R. Dubey, and p. srivastava, " synthesis characterization and catalytic Activity of cdo Nanocrystals", Material science and Engineering: B,Vol.176,no.2,pp.121-126,2001

[13]. C.H. Champness and C. H. Chan, "optimization of CdO Layer in a Se:CdO photovoltaic cell", solar Energy Materials and solar cells, vol. 37, no. 1. Pp. 75-92, 1995

[14]. M. Ristic, S .popovic, and S. Music, "Formation and properties of $\mathrm{Cd}(\mathrm{OH}) 2$ and CdO particles," Mater. Lett, vol. 58, no.20, pp. 2494-2499, 2004. 